\title{
El surgimiento de la teología cristiana y la separación de los caminos entre judaísmo y cristianismo (II) ${ }^{1}$
}

\author{
Emanuel Fiano* \\ Fordham University - New York (EEUU) \\ emfian@gmail.com \\ Recibido 09.07.2020/ Aprobado 11.09.2020 \\ DOI: https://doi.org/10.46553/teo.57.133.2020.p37-52
}

RESUMEN:

A través del presente artículo en dos partes me propongo emprender un examen del papel que las controversias trinitarias del cuarto siglo jugaron en determinar el alejamiento entre judíos y cristianos en la antigüedad tardía. Este ensayo propone que nuevas particiones surgieron dentro de lo que podríamos llamar el continuum cristiano-judío, gracias a las novedosas prácticas intelectuales desarrolladas por los cristianos durante esos debates para expresar sus ideas sobre Dios. Desde el punto de vista del contenido teológico, las disputas trinitarias permanecieron dentro del continuum de judaísmo y cristianismo: ninguna de las opciones teológicas exploradas por los cristianos habría sido fuente de particular escándalo para un judío contemporáneo a raíz de su particular articulación de lo divino. Sin embargo, al abandonar algunos modos argumentativos que oficiaban de puentes entre discursos protorabínicos y protocristianos, la producción de un campo teológico por parte de los creyentes en Jesús determinó que el cristianismo y el judaísmo se constituyan en tradiciones intelectuales diferenciadas.

Palabras clave: Controversias trinitarias; Judaísmo; Cristianismo; Nicea; Rabinismo The Emergence of Theology and the Parting of the Ways

- Emanuel Fiano es Assistant Professor de Estudios siríacos en el Departamento de Teología de la Universidad de Fordham, en Nueva York. Su investigación se enfoca en la historia intelectual del cristianismo en la antigüedad tardía, con particular atención a las literaturas siríaca y copta, a las controversias religiosas y a las relaciones entre judaísmo y cristianismo.

1 Quiero agradecer a la Dra. Gabriela Goldin Marcovich (Duke University) por su atenta y rigurosa revisión lingüística. 


\section{ABSTRACT}

With this article in two parts I hope to open up an examination of the role played by the fourth-century Trinitarian controversies in the late ancient estrangement between Jews and Christians. The article proposes that new partitions emerged in Judaeo-Christianity thanks to the novel practices that during the Trinitarian controversies Christians developed to express their ideas about God. From the viewpoint of theological content, the Trinitarian disputes persisted within a lasting Christian-Jewish continuum: none of the theological options explored by Christians would have caused particular scandal to a contemporaneous Jew on account of its particular articulation of divine reality. Nevertheless, by disengaging from earlier modes of argumentation functioning as bridges between proto-rabbinic and proto-Christian discourses, the production of a theological field on the part of believers in Jesus was largely responsible for the separate constitution of Christianity and Judaism as intellectual traditions.

Keywords: Trinitarian Controversies; Judaism; Christianity; Nicea; Rabbinism

\section{La separación de los caminos del conocimiento}

La combinación de escalas y planteamientos utilizados por una lectura histórica determina a menudo su potencial interpretativo y sus limitaciones. Observadas desde la distancia y a través de un planteamiento histórico-dogmático, las controversias trinitarias han sido interpretadas por algunos como un choque entre partidarios y contrincantes de Ario, si bien con un abanico de posturas. Los primeros intentos contemporáneos de dar inteligibilidad a estos debates -los trabajos pioneros de Adolf von Harnack, Eduard Schwartz, Theodor Zahn, Hans-Georg Opitz y Friedrich Loofs, producidos entre finales del siglo XIX y principios del siglo XX- los interpretaron como una sola y única crisis. En esta lectura, ésta se desenvolvió de manera sistemática, guiada por una lógica transparente. Sin embargo, esta interpretación no tomaba en cuenta las maneras en las que las trayectorias teológicas precedentes a las controversias trinitarias afectaron el surgimiento de las disputas mismas. Esta narrativa tampoco explicaba las volubles y continuas reconfiguraciones de alianzas eclesiásticas a lo largo de toda la crisis. ${ }^{2}$

2 Cf. John Henry Newman, The Arians of the Fourth Century. Sobre el modo en el que Newman trata la división entre las escuelas antioquena y alejandrina con respecto a las disputas trinitarias $c f$. Benjamin John King, Newman and the Alexandrian Fathers, 70-126. 
Nuevos planteamientos que aplicaban escalas distintas como lo fueron las síntesis históricas publicadas en la segunda mitad del siglo XX -primariamente por Manlio Simonetti y Richard Patrick Crosland Hanson ${ }^{3}$ - han afinado esta imagen, identificando distintas fases bien definidas dentro del debate. Como consecuencia, hoy en día se suele criticar las primeras interpretaciones de la controversia y se alega que existió en realidad una pluralidad de debates interconectados. Sin embargo, incluso estas perspectivas más recientes no abordan los cambios significativos que las controversias conllevaron en las maneras en las que los cristianos discutían de la divinidad.

Una renovada perspectiva unitaria sobre las controversias trinitarias puede permitir un reexamen de elementos de discontinuidad relativos a la producción intelectual precedente. Los modos de investigar las relaciones trinitarias y los presupuestos que los actores tenían sobre la manera correcta de llegar a un acuerdo no eran compartidos a priori entre los participantes del debate. Las perspectivas variadas sobre la relación de Cristo con el Padre y el cosmos eran expresadas en formas a partir de las cuales no se podía obtener fácilmente una síntesis. Estas formulaciones distintas podían conformar una discusión sólo si las lógicas subyacentes eran conmensurables. La admisión de estos diferentes actores a un espacio polémico estaba condicionada a la reconfiguración lógica del problema en cuestión en términos a través de los cuales todas las posturas del conflicto pudiesen expresarse.

Ya desde hace mucho tiempo los clasicistas consideran al cuarto siglo como un periodo de debilitamiento intelectual en el imperio romano. ${ }^{4}$ El decrecimiento en la producción literaria de esta era pone aún más de relieve las febriles actividades intelectuales de los cristianos en el periodo entre principios de los años 320 y el año

3 Manlio Simonetti, La crisi ariana; y Richard Patrick Crosland Hanson, The Search.

4 Cf. por ejemplo Ramsay MacMullen, «Sfiducia nell'intelletto». Sobre el papel de la literatura en la sociedad romana del cuarto siglo $c f$. Lieve Van Hoof y Peter Van Nuffelen, «The Social Role». Sobre las obras teológicas del cuarto siglo cf. Albrecht Dihle, Greek and Latin Literature, 539-553. 
$383 .{ }^{5}$ Estas actividades tomaron una variedad de formas, incluida la emisión de un sinfín de cartas sinodales, el intercambio de epístolas y la publicación de tratados doctrinales. ${ }^{6}$ Desde el punto de vista de la "alta cultura", la producción teológica cristiana constituyó el corpus literario más visible del cuarto siglo gracias a estos debates. Prescindiendo del partido doctrinal de los escritores, la densidad misma de cientos y posiblemente miles de transacciones literarias condujo a la creación de un campo separado, sostenido por intelectuales especializados. ${ }^{7}$

La separación de los caminos entre el cristianismo y el judaísmo fue el resultado de la divergencia entre dos tradiciones intelectuales cuyos exponentes más ilustrados prefirieron jugar distintos juegos de verdad. ${ }^{8}$ Durante las controversias trinitarias del cuarto

5383 es la fecha de la presentación de las cuatro declaraciones de fe al emperador Teodosio por parte de los obispos Nectario, Eunomio, Demófilo y Eleusio (respectivamente un ortodoxo, un hetereusiano, un homeo y un macedoniano). Rowan D. Williams, Arius, 48-61 ha ofrecido un argumento en favor de una reorganización del orden cronológico de los primeros Urkunde (las

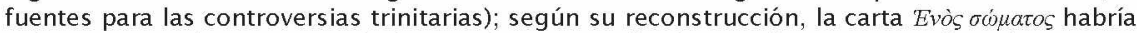
sido escrita recién en 325 . Se le ha comúnmente atribuido este documento a Alejandro mismo; George Christopher Stead, «Athanasius' Earliest Written Work» lo atribuye en vez a Atanasio.

6 Mark Vessey, «The Forging of Orthodoxy» contiene una interesante propuesta sobre el nuevo "orden de los libros" inaugurado por los cristianos en el siglo IV.

7 Así como lo ha demostrado la recepción crítica de Jacques Le Goff, Los intelectuales, la aplicación del término "intelectual", acuñado recién en el siglo diecinueve, a fenómenos modernos no está exenta de problemas (para la recepción crítica de esta obra cf. los ensayos colectados en II comportamento dell'intellettuale, en particular la introducción al volumen). Descartando el renacimiento carolingio del octavo y noveno siglo como fenómeno cortesano y restringido, Le Goff vio en el florecimiento de los estudios en París y Chartres del siglo XII la primera afirmación de una clase de intelectuales urbanos, «quienes tienen por oficio pensar y enseñar su pensamiento» (ibid., 21). En el siglo XIII, las universidades en las que esos enseñantes se juntaban desarrollarían sus métodos escolásticos, organizarían sus prácticas materiales y afirmarían su poder institucional frente a las autoridades seculares y eclesiásticas. Adoptar la palabra "intelectuales" para describir la red de líderes eclesiásticos capaces de dominar los métodos de un nuevo estilo de investigación teológica no nos obliga a fechar en la antigüedad tardía la emergencia de una intelectualidad en la cultura europea. Tocará a los historiadores medievales el papel de evaluar si la clase de los pensadores cristianos instruidos constituía o no un grupo social con el cual los intelectuales altomedievales y de las épocas siguientes se encontraban en continuidad objetiva.

8 Sobre el concepto de "juegos de verdad" cf. la entrevista de Michel Foucault, «L'Éthique du souci de soi». La "tradición" descrita en estas páginas no es ni la "tradición con vida" de Alasdaire MacIntyre's (definida en Tras la virtud, 293 como «una discusión históricamente desarrollada y socialmente incorporada, que en parte versa sobre los bienes que constituyen esa tradición») ni la "tradición discursiva" de Talal Asad, declinada más bien biopolíticamente (y constituida esencialmente por «discursos que intentan instruir los practicantes sobre la forma y el fin correctos de una práctica dada»: cf. Talal Asad, The ldea, 14). A pesar de reconocer que en el establecimiento del cristianismo como tradición independiente de investigación están en juego valores que exceden a la vida desencarnada de las mentes de unos obispos (y entre ellos ciertamente valores como la justicia y la moralidad social, centrales en el proyecto de Maclntyre) y de admitir que una serie de intereses religiosos gana terreno y se afirma hegemónicamente sobre todo a 
siglo, los nuevos métodos para la producción del conocimiento implementados por los líderes eclesiásticos hicieron que la teología emergiera como método de investigación, lo que acarreó la producción de un campo discursivo que atravesaba fronteras doctrinales partidarias, junto al establecimiento de una clase de intelectuales dedicada a las actividades teológicas. ${ }^{9}$

En este relato, se le asigna prioridad de causalidad histórica al lado de los seguidores de Jesús dentro del continuum cristiano-judío porque el cambio transcendental que Constantino imprimió sobre la cristiandad inició un proceso de integración entre la Iglesia y el gobierno imperial. De hecho, fue gracias a la acción del emperador que algunos de los métodos de trabajo ya dominados por los pensadores cristianos llegaron a arraigarse en una estructura institucional singularmente privilegiada por el poder político.

Las nuevas prácticas que este desarrollo implicó incluían el recurso a los concilios para tomar decisiones con respecto a desacuerdos doctrinales; ${ }^{10}$ la evolución de la forma del sínodo en un cuerpo judicial encargado no sólo de resolver cuestiones de doctrina sino también de juzgar miembros individuales del clero; ${ }^{11}$ la cre-

través de los medios de control social que Asad toma prestados del inventario foucaultiano, prefiero enfocarme aquí en otro objeto, es decir, en el cristianismo como tradición intelectual. Este concepto debe entenderse aproximadamente como análogo a lo que Larry Laudan, basándose en los trabajos de Thomas Kuhn e Imre Lakatos, ha nombrado una "tradición de investigación" ("research tradition"), definiéndola como «una serie de as untos generales sobre las entidades y los procesos en un campo de estudio y sobre los métodos apropiados que hay que utilizar para investigar los problemas y construir las teorías en ese campo» (Larry Laudan, Progress and its Problems, 80-81).

9 Hay constancia de fenómenos complejos de negociación, entremezclamientos y atravesamientos de las delimitaciones entre creyentes cristianos y judíos incluso después del final de la antigüedad tardía. Aunque estos ejemplos de interacción perdurable exceden al enfoque de este ensayo, tengo que notar que acercamientos más flexibles a la identidad religiosa, si bien pueden haber prevalecido por largo tiempo en la sociedad, no terminaron por afirmarse. El modelo que propongo asigna un papel prominente a las actividades y a la autopercepción de elites altamente letradas para determinar lo que devino del continuum entre las tradiciones cristiana y judia. Por lo tanto, este modelo asume la eficacia del poder de los líderes religiosos. Sobre la participación de las masas laicales en los debates teológicos del cuarto siglo $c f$. Rebecca Lyman, «Lex Orandi»; Daniel Ullucci, «What Did He Say? »; Michel-Yves Perrin, Civitas confusionis; y Jack Tannous, The Making of the Medieval Middle East, 11-43.

10 Sobre el hecho de que los concilios no eran una institución generalizada antes del cuarto siglo $c f$. Lewis Ayres, Nicaea and its Legacy, 85. Sobre los primeros concilios $c f$. Ramsay MacMullen, Voting about God. Sobre la expansión de la institución del concilio durante el siglo IV cf. Thomas Graumann, «The Conduct of Theology», 542-543.

11 Cf. Hasso Jaeger, «La preuve judiciaire», 522-529. 
ciente institucionalización de la Iglesia; ${ }^{12}$ y el establecimiento -por medio de viajes e intercambios epistolares- de alianzas episcopales trans-regionales, mediadas por la concesión, revocación y negación de la comunión sacramental. Al considerar el relato político e institucional a través de las prácticas de la clase intelectual, el relato que aquí se propone erosiona la imagen de un emperador quien por medio de su sola voluntad determinó de un plumazo la existencia del cristianismo y del judaísmo, trazando así entre ellos la frontera de la ortodoxia. Pese a ello, es razonable suponer que, si no hubiera sido por políticas imperiales amigables, no se habría observado la constitución independiente de una tradición intelectual cristiana en el siglo cuarto.

Dejar de lado la religión como categoría histórica útil para esta investigación no supone sin embargo una negación del hecho que los problemas que judíos y cristianos intentaban solucionar pertenecían a una tipología que, a partir de la modernidad tardía, vendría a ser definida como religiosa. ${ }^{13}$ El continuum del cual las dos tradiciones intelectuales emergieron se sustentaba en la interacción intelectual con una estructura conceptual compartida, que ambas heredaban del judaísmo del segundo templo, es decir el monoteísmo. ${ }^{14}$ A partir del momento en el que se postulaba una divinidad

12 Este proceso había sido favorecido por la afirmación del monoepiscopado en el tercer siglo. Sobre este fenómeno of. Jan N. Bremmer, The Rise of Christianity, 66; Alberto Camplani, «Le trasformazioni»; Alastair C. Stewart, The Original Bishops; y Emiliano Rubens Urciuoli, Servire due padroni, 133-136. Sobre la relación entre la afirmación del monoepiscopado y la constitución de los archivos cristianos cf. Alberto Camplani, «Setting a Bishopric».

13 Sobre la categoría de religión en relación a la antigüedad tardía cf. Brent Nongbri, Before Religion, con más referencias bibliográficas. Sobre la misma categoría en relación al estudio del judaísmo antiguo of. Daniel Boyarin, Judaism.

14 Cierto es que ideas monoteístas pueden encontrarse también en fenómenos religiosos de la antigüedad tardía sin ninguna relación con el campo judío (fenómenos llamados "paganos" por los cristianos); sin embargo, el modelo propuesto aquí no está fundamentado en una tipología fenomenológica, sino más bien toma a los actores sociales pertenecientes a las elites como sus referencias históricas. En años recientes el cuerpo de estudios sobre la cuestión del monoteísmo "pagano" ha crecido notablemente: of. Polymnia Athanassiadi y Michael Frede, Pagan Monotheism; Stephen Mitchell y Peter Van Nuffelen, Monotheism between Christians and Pagans; Eid., One God; y Peter Van Nuffelen, «Beyond Categorisation» ( $c f$. también Erik Peterson, Heis theos, que a pesar de los años sigue siendo fundamental). La etiqueta de "monoteísmo pagano" ha sido adoptada para expresiones ni cristianas ni judías de «creencia en los poderes de una divinidad única y suprema, aunque sin excluir necesariamente a todos los otros dioses", una creencia que habría «constituido la base de la mayoría de las formas de religión en el mundo romano del cuarto y quinto siglo A.D». (Stephen Mitchell y Peter Van Nuffelen, Monotheism between Christians 
dotada de subjetividad, ¿cómo había que entender su relación con la humanidad ${ }^{15}$ Los judíos no seguidores de Jesús compartían con los judíos y los gentiles que creían en él la necesidad urgente de solucionar estas tensiones teóricas.

Sería absurdo pintar a los judíos rabínicos de la antigüedad como incapaces de -o desinteresados en- ocuparse de este dilema. El enfoque en una comprensión discursiva de lo divino no era de ninguna forma prerrogativa exclusiva de los pensadores cristianos. ${ }^{16}$ De hecho, las fuentes judías exhiben una clara preocupación con Dios y sus actividades (es notorio, por ejemplo, que los rabinos se dedicaron inclusive a analizar el pormenor de la agenda cotidiana de Dios). ${ }^{17}$ Sin embargo, alrededor del cuarto siglo, actores históricos separados entre sí por su decisión de seguir o no a Jesús empezaron a interactuar con el dilema monoteísta desde ángulos disciplinarios distintos.

Los cristianos comenzaron a usar sus propios métodos para tratar los mismos problemas teóricos que ocupaban las mentes de los judíos. Sus pesquisas se cristalizaron en un estilo de investigación regido por una serie de reglas y sostenido por un patrón coherente de interacción intelectual, un estilo de investigación destinado a producir un campo discursivo distintivo. ${ }^{18}$ Mientras tanto, los rabinos se mantuvieron en su empeño, usando métodos de trabajo intelectual compatibles con aquellos adoptados previamente por los

and Pagans, 1). Este modelo ha sido criticado, a veces con buenos argumentos: $c f$. por ejemplo Giulia Sfameni Gasparro, «Monoteismo pagano»; Maria Vittoria Cerutti, «Unità del divino»; Ead., "Monoteismo pagano?» y otros más entre los estudios juntados en Charles Guittard, Le monothéisme. Cf. también la pugnaz pero interesante reseña del volumen editado por Mitchell y Van Nuffelen contenida en Colin Wells, «Spotting an Elephant».

15 Las razones de esta tensión podrían haber tenido que ver tanto con una lógica intrínseca del monoteísmo como con los orígenes de su variante judía (un problema irrelevante para esta discusión), ya sea que esos orígenes deban ser buscados en el contexto cananeo de la religión is raelita pre-exílica, o, como lo sugiere Jan Assmann, en la cultura egipcia ( $c f$. por ejemplo Jan Assmann, Of God and Gods).

16 Cf. David Charles Kraemer, «Concerning the Theological Assumptions of the Yerushalmi», 355-356.

17 B. Abodah zarah 3b. Sobre Dios en el judaísmo rabínico $c f$. Maurizio Mottolese, Dio nel giudaismo rabbinico.

18 Esto no elimina la posibilidad de que los estilos de los teólogos cristianos y de los rabinos compartiesen presupuestos epistemológicos. 
cristianos. A la larga, el desarrollo de dos estilos dispares, ligados cada uno a un contexto institucional, abrió brechas para dos campos discursivos distintos, pero que pertenecían al mismo universo discursivo (e interactuaban en la realidad social). ${ }^{19}$ A través de estos procesos, emergieron dos tradiciones intelectuales. Los cristianos habían adoptado la teología, los judíos no.

Aunque en un principio no le hubieran dado ese nombre, los cristianos llevaban practicando la "teología" sensu lato desde hacía largo tiempo. ${ }^{20} \mathrm{Al}$ fin y al cabo, los creyentes en Jesús habían articulado desde épocas tempranas una variedad de concepciones sobre Dios, el mundo y la identidad de Cristo. ¿Acaso no era el autor del Evangelio de Juan, a quien por lo menos a partir del siglo IV se le conocía por ó $\theta \varepsilon o \lambda o ́ \gamma o \varsigma$ (el teólogo), quien ya en el primer siglo había inscrito en el Prólogo de su narración una de las líneas más transcendentes de la historia de la interpretación cristiana, «En el principio era el Verbo, y el Verbo estaba ante Dios, y el Verbo era Dios»?

19 Para una conceptualización diferencial de universo discursivo, campo discursivo y espacio discursivo of. Dominique Maingueneau, Sémantique de la polémique. A pesar de la inspiración foucaultiana de Maingueneau, mi adopción de la categoría de discurso no trata primariamente el cristianismo como un sistema totalizante de poder, dotado de efectos de verdad y consecuencias para la construcción del sí. Por discurso entiendo aquí más sencillamente una serie de códigos lingüísticos relacionados con prácticas particulares, movilizadas por sujetos históricos identificables.

20 Como lo nota Christoph Markschies, Christian Theology, 5-19, los pensadores cristianos

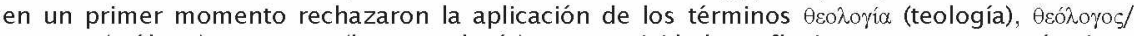

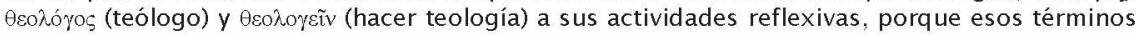
habían designado durante un largo tiempo las actividades de quienes componían o recitaban cultualmente enseñanzas mitológicas e himnos sobre los dioses. Es probable, sin embargo,

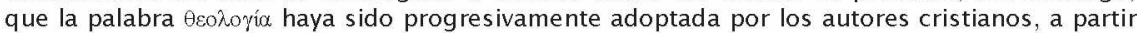
de Justino Mártir, gracias a su fuerte asociación platónica. A partir del tardío siglo III, el campo semántico de $\theta \varepsilon o \lambda o \gamma i ́ a$ pasó a indicar una reflexión sobre relaciones intra-divinas, siguiendo las huellas de su utilización por parte de Clemente de Alejandría y, sobre todo, de Orígenes. En un

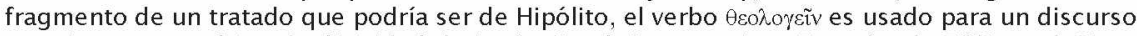
que tiene como objeto la divinidad de Jesús. En el Comentario a Zacarías de Dídimo el Ciego

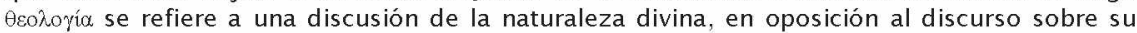
manifestación económica (una distinción mantenida en la teorización de Eusebio de Cesarea, en la cual la teología se volvía una sub-disciplina de la filosofía). En la época de Eusebio, $\theta \varepsilon o \lambda o \gamma i ́ a$ empezó a indicar también el pensamiento cristiano perseguido en función anti-herética y con la validación dogmática de un sínodo o un concilio. Esta exploración terminológica, en todo caso, tiene un interés marginal para este estudio, en la medida en la que las elecciones lexicales conscientes de los autores en la representación de su trabajo intelectual corren el riesgo de ofuscar las concreciones que emergen de sus textos, y que son sintomáticas de cambios más amplios. Sobre $\theta \varepsilon$ chơi y términos relacionados en la literatura cristiana antigua cf. también Joseph Stiglmayr, «Mannigfache Bedeutung»; Ferdinarnd Kattenbusch, «Die Entstehung»; y Frank Whaling, «The Development» (todos cit. por Markschies). 
Escritos cristianos del segundo y tercer siglo cuales la Ascensión de Isaías, las Odas de Salomón, las Epístolas de Ignacio de Antioquía, el Pastor de Hermas y las Actas de Pedro atestiguan de una rica reflexión sobre la cuestión de la identidad de Cristo. Christoph Markschies, haciendo hincapié en una distinción entre teología implícita y explícita -que ve a la primera como esencial para cualquier cultura religiosa ${ }^{21}$-, remarca que el segundo y tercer siglo mostraron «una creciente explicación de la 'teología implícita" «.22 Si así es, ¿cómo podría colocarse la emergencia del discurso teológico en una fecha tan tardía como el cuarto siglo?

Se puede esbozar una respuesta si se considera que la teología a la que se refiere el presente ensayo no es el esfuerzo individual de unos eruditos creyentes en Jesús para comprender racionalmente su fe, ya sea a través de medios "implícitos" o "explícitos". Más bien, se trata de describir una disciplina de estudio que derivaba de las prácticas y de los métodos, siempre más compartidos y regulados, utilizados por los que buscaban esta comprensión. El término "teología", por lo tanto, se refiere aquí a la forma particular que esta actividad asumió durante el cuarto siglo en manos de intelectuales creyentes en Jesús involucrados en una controversia sobre las relaciones del Hijo (y más tarde del Espíritu Santo) con Dios Padre.

A partir del quinto siglo, el nuevo estilo de investigación que había emergido durante el siglo anterior empezó a ser llamado "teología", sobre todo gracias a la mediación de Agustín. Sucesivamente el término fue universalizado y aplicado retroactivamente a formas antecedentes de reflexión sobre el Dios cristiano. Por lo tanto, definir como "teología" a la nueva manera de hablar de lo divino que los cristianos desarrollaron en el siglo IV implica intentar explicar los procesos que hicieron que el significado de la palabra fuese estabilizado, para ser más tarde transmitido a la tradición intelectual cristiana. Al mismo tiempo, es importante remarcar que

21 Cf. Jan Assmann, The Search for God, 10-12.

22 Cf. Christoph Markschies, «Intellectuals and Church Fathers»; e Id., Christian Theology, 4. 
esta concepción de la teología tiene el potencial de iluminar las consecuencias históricas y el impacto de esos desarrollos sobre la separación de los caminos entre el cristianismo y el judaísmo.

En cualquier época de controversia, los campos sociales e intelectuales se ven disgregados por sectarismo e incluso por violencia. Las controversias, sin embargo, pueden funcionar también como rituales involuntarios, a través de los cuales las comunidades, eventualmente reconciliadas, establecen sus propios límites. El campo discursivo, por ende, al fragmentarse en desacuerdos teóricos, se auto-constituye mediante el intercambio intelectual. En los debates trinitarios del cuarto siglo, creyentes cristianos que inicialmente se consideraban hermanos empezaron repentinamente a verse el uno al otro como enemigos y herejes. Por otro lado, poco tiempo después del Concilio de Constantinopla (381) la cacofonía del combate trinitario se sosegó. Incluso en las regiones del imperio romano en las que permaneció una presencia anti-constantinopolitana, la batalla había terminado. ${ }^{23}$ Los gritos de guerra de homousianos, homeusianos, homeos y heterousianos; los eslóganes de los así llamados arianos, marcelianos, eustacianos, eusebianos, eunomianos, atanasianos y macedonianos; las invectivas mutuas de occidentales y orientales; las misivas inspiradoras de los ardientes defensores del pro-nicenismo; la "curiosidad indiscreta" de los simpatizantes laicos anti-nicenos ${ }^{24}$-todas las voces que habían resonado durante décadas- se desvanecieron. En ese mismo tiempo, las fronteras intelectuales del cristianismo imperial llegaron a coincidir en medida substancial con aquellas del campo de batalla dentro del cual el conflicto trinitario se había desenvuelto. Todos aquellos que habían preferido quedarse fuera de las disputas, no teniendo interés en una contienda para establecer la identidad de Cristo en términos ontológicos, habían de hecho sancionado su enajenamiento del campo in-

23 Fuera del imperio romano el "Arianismo" se había difundido entre los godos: $c f$. Manlio Simonetti, Studi sull'arianesimo; Id., "Arianesimo latino"; y Bruno Luiselli, "Dall'arianesimo dei Visigoti".

24 Cf. Richard Lim, Public Disputation, 149-182. 
telectual de la cristiandad imperial. Ésta fue, naturalmente, la senda tomada por los judíos no seguidores de Jesús.

Todas las opciones doctrinales que estaban bajo consideración durante los debates trinitarios podían ser reconciliadas con la serie de creencias que ligaban el cristianismo al legado del judaísmo. Lo que impulsó la divergencia entre el cristianismo y el judaísmo durante esos debates no fue una supuesta afinidad por algún contenido teológico particular, sino la emergencia de la teología como modo de investigar, encarnado en prácticas específicas de producción del saber religioso.

Al enfatizar los credos pronunciados por los concilios, que recombinaban y ponían en diálogo distintas tradiciones teológicas geo-culturales, y al desarrollar un conjunto coherente y especializado de reglas para la discusión doctrinal, los protagonistas de estas controversias contribuyeron a crear un campo cultural trans-partidario. Estas operaciones discursivas, heredadas por la tradición intelectual cristiana, se convirtieron en una parte de su identidad tan duradera como los artículos de fe contenidos en el credo niceno-constantinopolitano. Las controversias trinitarias marcaron un hito no sólo en la formación del dogma cristiano, sino también en la emergencia de las reglas que rigen el intercambio de las ideas teológicas. La coherencia y la distinción cada vez mayores observables en el campo discursivo que se produjo en consecuencia trajeron consigo la aparición de particiones siempre más claras dentro del continuum judío-cristiano de la antigüedad tardía.

\section{Bibliografía}

Asad, Talal. The Idea of an Anthropology of Islam. Washington (DC): Center for Contemporary Arab Studies, Georgetown University, 1986.

Assmann, Jan. The Search for God in Ancient Egypt. Translated by David Lorton. Ithaca (NY): Cornell University Press, 2001 [= 
Translation of Ägypten. Theologie und Frömmigkeit einer frühen Hochkultur. Stuttgart: Kohlhammer, 1984].

- Of God and Gods: Egypt, Israel, and the Rise of Monotheism. Madison (WI): University of Wisconsin Press, 2008.

Athanassiadi, Polymnia and Michael Frede, eds. Pagan Monotheism in Late Antiquity. Oxford: Clarendon Press, 1999.

Ayres, Lewis. Nicaea and Its Legacy: An Approach to Fourth-Century Trinitarian Theology. Oxford: Oxford University Press, 2004.

Boyarin, Daniel. Judaism: The Genealogy of a Modern Notion. New Brunswick (NJ): Rutgers University Press, 2018.

Bremmer, Jan N. The Rise of Christianity through the Eyes of Gibbon, Harnack and Rodney Stark. Groningen: Barkhuis, 2010.

Brennecke, Hanns Christof, Uta Heil, Annette von Stockhausen, and Angelika Wintjies. Athanasius Werke. Dritter Band. Erster Teil. 3. Lieferung. Berlin and New York: De Gruyter, 2007.

Camplani, Alberto. «Le trasformazioni del cristianesimo orientale: monoepiscopato e sinodi (II-IV secolo)». Annali di Storia dell'Esegesi 23 (2006): 67-114.

- , «Setting a Bishopric / Arranging an Archive: Traces of Archival Activity in the Bishopric of Alexandria and Antioch». Pages 231-272 in Manuscripts and Archives: Comparative Views on Record-Keeping. Edited by Alessandro Bausi, Christian Brockmann, Michael Friedrich, and Sabine Kienitz. Studies in Manuscript Cultures 11. Berlin: De Gruyter, 2018.

Cerutti, Maria Vittoria. «Monoteismo pagano? Elementi di tipologia storica». Adamantius 15 (2009): 307-330.

- - «Unità del divino e unicità del principio: aspetti della rappresentazione dell'altro». Annali di scienze religiose 8 (2003): 179-195.

Dihle, Albrecht. Greek and Latin Literature of the Roman Empire: from Augustus to Justinian. London and New York: Routledge, 1994.

Foucault, Michel. «L'Éthique du souci de soi comme pratique de liberté». Concordia: Revista internacional de filosofía 6 (1984), 96-116. 
Graumann, Thomas. «The Conduct of Theology and the 'Fathers' of the Church». Pages 539-555 in A Companion to Late Antiquity. Edited by Philip Rousseau. Oxford: Blackwell-Wiley, 2009.

Guittard, Charles, ed. Le monothéisme: diversité, exclusivisme ou dialogue? Association européenne pour l'étude des religions (EASR), Congrès de Paris, 11-14 septembre 2002. Paris: Éditions Non Lieu, 2010.

Hanson, Richard Patrick Crosland. The Search for the Christian Doctrine of God. The Arian Controversy 318-381. Edinburgh: T\&T Clark, 1988.

Il Comportamento dell'intellettuale nella società antica. Pubblicazioni dell'Istituto di filologia classica e medievale 67. Genua: Università di Genova, Facoltà di lettere, Istituto di filologia classica e medievale, 1980.

Jaeger, Hasso, «La preuve judiciaire d'après la tradition rabbinique et patristique". Pages 415-594 in Recueils de la Société Jean Bodin. Tome XVI. La preuve (antiquité). Bruxelles: Les Éditions de la Librairie Encyclopédique, S.P.R.L. 1965.

Kattenbusch, Ferdinand. «Die Entstehung einer christlichen Theologie.

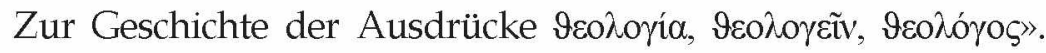
Zeitschrift für Theologie und Kirche N.F. 11 (1930): 161-205.

King, Benjamin John. Newman and the Alexandrian Fathers: Shaping Doctrine in Nineteenth-Century England. Oxford and New York: Oxford University Press, 2009.

Kraemer, David Charles. «Concerning the Theological Assumptions of the Yerushalmi». Pages 355-368 in vol. 3 of The Talmud Yerushalmi in Graeco-Roman Culture. 3 vols. Edited by Peter Schäfer. Texte und Studien zum antiken Judentum 71, 79, 93. Tübingen: Mohr-Siebeck, 2003.

Laudan, Larry. Progress and Its Problems: Toward a Theory of Scientific Growth. Berkeley: University of California Press, 1977.

LeGoff, Jacques. Los intelectuales en la Edad Media. Barcelona: Gedisa Editorial, 1986 (transl. of Id. Les intellectuels au moyen âge. Paris: Seuil, 1957).

Lim, Richard. Public Disputation, Power, and Social Order in Late Antiquity. Berkeley (CA): University of California Press, 1995. 
Luiselli, Bruno. «Dall'arianesimo dei Visigoti di Costantinopoli all'arianesimo degli Ostrogoti d'Italia». Rendiconti dell'Accademia Nazionale dei Lincei. Classe di Scienze morali, storiche e filologiche 16 (2005): 5-30.

Lyman, Rebecca. «Lex Orandi: Heresy, Orthodoxy, and Popular Religion». Pages 131-141 in The Making and Remaking of Christian Doctrine. Essays in Honour of Maurice Wiles. Edited by Sarah Coakley and David A. Pailin. Oxford: Clarendon Press, 1993.

MacIntyre, Alasdaire. After Virtue: A Study in Moral Theory. $3^{\text {rd }}$ ed. Notre Dame (IN): University of Notre Dame Press, 2007.

MacMullen, Ramsay. «Sfiducia nell'intelletto nel quarto secolo». Rivista storica italiana 84 (1972): 5-16.

- Voting about God in Early Church Councils. New Haven (CT): Yale University Press, 2006.

Maingueneau, Dominique. Sémantique de la polémique : discours religieux et ruptures idéologiques au XVIle siècle. Lausanne (Switzerland): L'Age d'homme, 1983.

Markschies, Christoph. «Intellectuals and Church Fathers in the Third and Fourth Centuries». Pages 239-256 in Christians and Christianity in the Holy Land: From the Origins to the Latin Kingdoms. Edited by Ora Limor and Guy Gedalyah Stroumsa. Cultural Encounters in Late Antiquity and the Middle Ages 5. Leiden: Brill, 2006.

- Christian Theology and Its Institutions in the Early Roman Empire: Prolegomena to a History of Early Christian Theology. Translated by Wayne Coppins. Waco (TX): Baylor University Press, 2015 [= Translation of Christoph Markschies, Kaiserzeitliche antike christliche Theologie und ihre Institutionen. Prolegomena zu einer Geschichte der antiken christlichen Theologie. Tübingen: Mohr Siebeck, 2007].

Mitchell, Stephen and Peter Van Nuffelen, eds. Monotheism between Christians and Pagans in Late Antiquity. Interdisciplinary studies in ancient culture and religion 12. Louvain and Walpole (MA): Peeters, 2010. 
- , eds. One God: Pagan Monotheism in the Roman Empire. Cambridge: Cambridge University Press, 2010.

Mottolese, Maurizio. Dio nel giudaismo rabbinico. Immagine e mito. Scienze e storia delle religioni 15. Brescia: Morcelliana, 2010.

Newman, John Henry. The Arians of the Fourth Century. London: E. Lumley, 1871.

Nongbri, Brent. Before Religion: A History of a Modern Concept. New Haven (CT): Yale University Press, 2013.

Perrin, Michel-Yves. Civitas confusionis : de la participation des fidèles aux controverses doctrinales dans l'Antiquité tardive (début IIIe s.c. 430). Paris: Nuvis, [2017].

Peterson, Erik, Heis theos. Epigraphische, formgeschichtliche und religionsgeschichtliche Untersuchungen zur antiken "Ein-Gott"-Akklamation. Göttingen: Vandenhoeck \& Ruprecht, 1926 [= Vol. 8 of Erik Peterson, Ausgewählte Schriften. 12 vols. Edited by Christoph Markschies, Henrik Hildebrandt, and Barbara Nichtweiss. Würzburg: Echter, 2012.

Sfameni Gasparro, Giulia. «Monoteismo pagano nella Antichità tardiva? Una questione di tipologia storico-religiosa». Annali di scienze religiose 8 (2003): 97-127.

Simonetti, Manlio. Studi sull'arianesimo. Verba Seniorum 5. Rome: Editrice Studium, 1965.

—, «Arianesimo latino». Studi medievali 8 (1967): 663-744.

—, La crisi ariana nel IV secolo. Studia Ephemeridis Augustinianum 11. Rome Institutum Patristicum Augustinianum, 1975.

Stead, George Christopher. «"Athanasius" Earliest Written Work». Journal of Theological Studies 39 (1988): 76-91.

Stewart, Alastair C. The Original Bishops. Office and Order in the First Christian Communities. Grand Rapids (MI): Baker Academic, 2014.

Stiglmayr, Joseph. "Mannigfache Bedeutung von "Theologie' und 'Theologen'». Theologie und Glaube 11 (1919): 296-309. 
Tannous, Jack. The Making of the Medieval Middle East: Religion, Society, and Simple Believers. Princeton (NJ): Princeton University Press, 2018.

Ullucci, Daniel. «What Did He Say? The Ideas of Religious Experts and the 99\%». In Religious Competition in the Third Century C.E.: Jews, Christians, and the Greco-Roman Worlds. Edited by Nathaniel P. DesRosiers, Jordan D. Rosenblum, and Lily C. Vuong. Journal of ancient Judaism Supplements 15. Göttingen: Vandenhoeck \& Ruprecht, 2014, 21-31.

Urciuoli, Emiliano Rubens. Servire due padroni. Una genealogia dell'uomo politico cristiano (50-313 e.v.). Saggi 101. Brescia: Morcelliana, 2018.

Van Hoof, Lieve and Peter Van Nuffelen. «The Social Role and Place of Literature in the Fourth Century AD». In Literature and Society in the Fourth Century AD: Performing Paideia, Constructing the Present, Presenting the Self. Edited by Lieve Van Hoof and Peter Van Nuffelen. Mnemosyne supplements. Monographs on Greek and Latin language and literature 373. Leiden: Brill, 2014, 1-15.

Van Nuffelen, Peter. «Beyond Categorisation. 'Pagan Monotheism' and the Study of Ancient Religion». Common Knowledge 18 (2012): 451-463.

Vessey, Mark. «The Forging of Orthodoxy in Latin Christian Literature: A Case Study». Journal of Early Christian Studies 4 (1996): 495-513.

Wells, Colin. «Spotting an Elephant». Arion 19 (2011): 159-172.

Whaling, Frank. «The Development of the Word 'Theology'». Scottish Journal of Theology 34 (1981): 289-312.

Williams, Rowan D. Arius. Heresy and Tradition. Grand Rapids (MI): Eerdmans, 2002. 